\title{
Editorial: Sociality in the Marine Environment
}

\author{
David M. P. Jacoby ${ }^{1,2 * t}$, Culum Brown ${ }^{3 \dagger}$, Darren P. Croft ${ }^{4 \dagger}$, Janet Mann ${ }^{5 t}$ and \\ Johann Mourier ${ }^{6+}$
}

\begin{abstract}
${ }^{1}$ Lancaster Environment Centre, Lancaster University, Lancaster, United Kingdom, ${ }^{2}$ Institute of Zoology, Zoological Society of London, London, United Kingdom, ${ }^{3}$ Department of Biological Sciences, Macquarie University, Sydney, NSW, Australia, ${ }^{4}$ Centre for Research in Animal Behaviour, College of Life and Environmental Sciences, University of Exeter, Exeter, United Kingdom, ${ }^{5}$ Department of Biology, Georgetown University, Washington, DC, United States, ${ }^{6}$ UMS 3514 Plateforme Marine Stella Mare, Université de Corse Pasquale Paoli, Biguglia, France
\end{abstract}

Keywords: grouping, social organization, network structure, interactions, marine societies, tracking

\section{OPEN ACCESS}

Edited and reviewed by: Angel Borja

Technological Center Expert in Marine and Food Innovation (AZTI), Spain

*Correspondence:

David M. P. Jacoby

d.jacoby@lancaster.ac.uk

tORCID:

David M. P. Jacoby orcid.org/0000-0003-2729-3811

Culum Brown

orcid.org/0000-0002-0210-1820

Darren P. Croft

orcid.org/0000-0001-6869-5097

Janet Mann

orcid.org/0000-0003-0664-175X

Johann Mourier

orcid.org/0000-0001-9019-1717

Specialty section:

This article was submitted to

Marine Ecosystem Ecology,

a section of the journal

Frontiers in Marine Science

Received: 27 January 2022 Accepted: 07 February 2022

Published: 28 February 2022

Citation:

Jacoby DMP, Brown C, Croft DP,

Mann J and Mourier J (2022) Editorial:

Sociality in the Marine Environment.

Front. Mar. Sci. 9:863595.

doi: 10.3389/fmars.2022.863595

\section{Editorial on the Research Topic}

\section{Sociality in the Marine Environment}

\section{INTRODUCTION}

Sociality is ubiquitous within the animal kingdom (Krause and Ruxton, 2002). It is well-established that social behavior serves a range of important evolutionary and ecological functions, from coordinating collective behaviors, maintaining group cohesion, and reducing predation risk to facilitating cooperation, reproduction, and establishing dominance hierarchies (Krause et al., 2007; Croft et al., 2008; Schürch et al., 2010; Shizuka and McDonald, 2012). Despite this, our current understanding of the structure, function, and mechanisms underpinning animal societies is disproportionately biased toward terrestrial species. Sociality however, occurs broadly across a diversity of marine taxa, some of which may hold the key to revealing the evolutionary origins of tetrapod social behavior.

But how do marine societies establish themselves, how do animals find and communicate with one another and how are long-lasting social bonds formed and maintained in such a dynamic environment? For example, sound travels efficiently over long distances in the marine environment, but visual signaling tends to be limited to very short distances. The basic physical properties of the marine environment hamper our ability to accurately estimate the size and structure of aggregations in marine animals, let alone determine how bonds are formed, maintained, and disrupted. Considering recent technological and analytical developments, this Research Topic (RT) is intended to showcase the very latest progress in revealing the complex social lives of marine organisms, from large-bodied migratory cetaceans to small territorial reef fishes. Bringing together 69 researchers from 55 institutions/organizations and 13 countries, the RT explores in 13 manuscripts the challenge of measuring meaningful associations in different species, while considering the biological, reproductive, and environmental drivers that structure marine animal groups. Contributions to this RT also reflect on anthropogenic effects that may impact how animals socialize underwater. While the indelible footprint of human activities on our marine ecosystems remains far from fully understood (Halpern et al., 2019; Elliott et al., 2020), these studies complement the wider literature facilitating a better understanding of population-scale processes that structure marine assemblages, an endeavor crucial to marine and species conservation moving forwards (Villegas-Ríos et al., 2022). 


\section{MEASURING ASSOCIATIONS}

In many instances, associations between organisms are defined based on the proximity between pairs of individuals and the longevity or frequency of this proximity (Franks et al., 2010; Haddadi et al., 2011). For large, migratory species like some cetaceans however, associations can be mediated over considerably greater distances via complex acoustic repertoires that underpin sophisticated social communities and even cultures (Rendell and Whitehead, 2001). While previous work on humpback whales (Megaptera novaeangliae) for example, focuses almost exclusively on the feeding (e.g., Allen et al., 2013) or breeding grounds (e.g., Pack et al., 2009), Franklin et al. offer insights into the apparent "black box" of humpback social behavior during their southern migration. Non-agonistic social behaviors associated with resting, gestation, and parental care, appear more prevalent than agonistic competitive social behaviors, reflecting largely the demography (i.e., few mature males) of the groups that form there (Franklin et al.). Cusano et al. however, undertake acoustic recordings at breeding grounds to shed light on how complex repertoires of acoustic signaling in $M$. novaeangliae mediate conflict and aggression when mature males are in direct competition for mates. They report that vocal repertoire and visual displays increased in complexity within "high intensity" groups with frequent turnover.

Clearly defined associations, that consider both the ecological and environmental context in which these associations occur, are at the core of any study into animal social behavior (Farine and Whitehead, 2015; He et al., 2019; Seebacher and Krause, 2019; Sosa et al., 2021). Consequently, this RT was intended to sit at the interface between methodological and ecological developments (Figure 1). Aspillaga et al. track the trajectories of 232 pearly razorfish (Xyrichtys novacula) using a state-of-the-art, high-resolution acoustic telemetry system to demonstrate harem-like social structure within this small coastal wrasse. Measuring associations from paired proximities down to a scale of $1 \mathrm{~m}$, social organization was hypothesized to be underpinned by male agonistic behaviors (Aspillaga et al.). Further emphasizing the link between movement and social behavior, a study on the Mediterranean Rainbow Wrasse (Coris julis) used in situ displacement experiments, focal follows, and stereovideography to measure female aggression toward displaced neighboring (low aggression) and non-neighboring (high aggression) female conspecifics routing back toward their own territories (Goverts et al.).

\section{GROUP SIZE, STRUCTURE, AND COMPOSITION}

The size of animal groups can have far-reaching implications for individual social behavior, as well as population-level social structure; in fact, it is often controlled for, both experimentally and analytically, in studies of animal social networks (Croft et al., 2011). Determining group size underwater however can be difficult. When studying the surface behavior of marine cetaceans, photo ID, and observerbased counts are frequently used to quantify groups. Yet a comparative study by Liu, Lin, Tang, et al. demonstrates that group size estimates using both approaches, can be biased by a combination of methodological and biogeographical variances. From data on Indo-Pacific humpback dolphins (Sousa chinensis), Liu, Lin, Lusseau, et al. document how variable group size can be within a population displaying fission-fusion behavior. Group size appeared to vary both seasonally and inter-annually, as well as in response to the number of mother-calf pairs present (Liu, Lin, Lusseau, et al.), reiterating behavioral segregation in some cetacean species groups (Galezo et al., 2018). Given the degree of both intra-species and intra-population group size variability and composition, it remains challenging to establish the functional significance and mechanistic drivers of sociality in many species. The link between this variation itself and other ecological variables however, might also help reveal social mechanisms in future studies.

Sociality can extend beyond one's species. For example, birds (Sridhar et al., 2009) and a range of mammals (Goodale et al., 2017) are often in mixed species groups (MSG). In reviewing 203 studies on the functional significance of cetacean MSG, Syme et al. thus argue for better standardization of methods, and put forward a conceptual framework that outlines more distinct, shared terminology across studies of MSGs. This is vital as mixedspecies associations will impact the costs and benefits of group living.

Given the difficulties in tracking wide-ranging marine organisms, other species, such as coral reef fishes, can shed light on the evolutionary foundations of marine sociality. Rueger et al. offer a comprehensive journey through the past two decades of developments in this area; their review explores ways in which some reef fishes have become model species with which to test fundamental theories of social evolution including kin selection, cooperative breeding, and sociality with mutualistic partner species (Rueger et al.).

Throughout this RT, social network analyses (SNA) have played a prominent role in better understanding marine sociality. An extensive systematic review of social network structure in toothed whales (Odontoceti), reveals the unifying feature of this group as having relatively densely connected, population-level social networks, with fairly rapid fissionfusion dynamics. Based on a subset of species within this group that have been well-studied (pilot whales, killer whales, sperm whales, and bottlenose dolphins), networks were typically mixed sex units of maternal kin (Weiss et al.). In another well-studied marine predator, Anderson et al. utilize acoustic telemetry and SNA to demonstrate non-random and non-resource-driven, co-occurrences, and community structuring amongst juvenile white sharks (Carcharodon carcharias), suggesting that even in wide-ranging, fissionfusion apex predators, group membership during early ontogeny may serve important ecological functions in later life. 


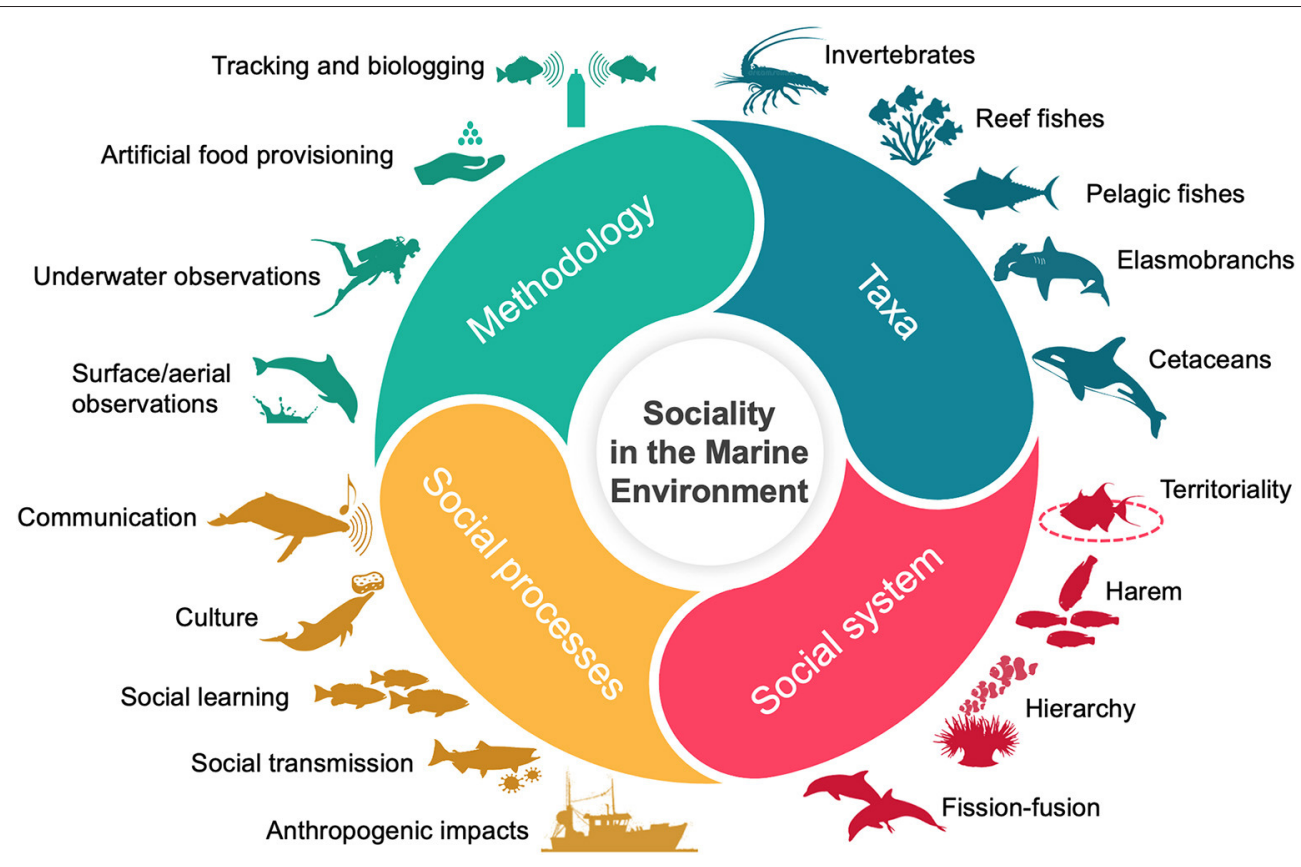

FIGURE 1 | The diversity of sociality in marine species. This RT collates papers from a broad range of species, with different social systems that occupy diverse habitat types. There is an emphasis on the technological and analytical developments required to explore the implications of sociality in the context of ecology, evolution, and conservation within an environment that is increasingly impacted by human activities.

\section{ANTHROPOGENIC INFLUENCES ON SOCIALITY}

Undeniably, humans are altering the marine environment, from ocean chemistry (Andersson et al., 2005) and reef habitat complexity (Perry and Alvarez-Filip, 2019), to marine soundscapes (Duarte et al., 2021). In an attempt to better connect people with some of the many threats facing the marine environment and its fauna, diving, and boat-based ecotourism has exploded in recent decades. This RT pulls together three studies that reflect on both the opportunities offered and potential consequences of tourism on the structure and behavior of elasmobranchs provisioned with food for tourists. Jacoby et al. explore aggregation behavior and the distinct social preferences of wide-ranging tiger sharks (Galeocerdo cuvier) gathering at a tourism provisioning site. Aggregations were longer lasting and more frequent, and gregariousness more variable at tourist sites, although non-random social preferences occurred outside of the tourism season and were highly variable between individuals potentially mitigating any long-lasting impacts of tourism (Jacoby et al.). Two further studies took advantage of tourism activities to quantify inter-individual interactions and hierarchies in species that would be difficult under "normal" wild conditions. From 13 years of dive observation and photo ID data, Bouveroux et al. show preferred, long-term companionships in another apex predatory elasmobranch, the bull shark (Carcharhinus leucas), also measured using SNA that control for potential non-social drivers of aggregation. Avoidance behavior was also observed in this species, suggestive of a potential dominance hierarchy when food is made available. The question of social dominance is explicitly tested by Pini-Fitzsimmons et al., who combine social network theory and hierarchy (heterarchy) to explore the agonistic social interactions of smooth stingrays (Bathytoshia brevicaudata) competing for food provisioned at a shallow, coastal location. Heterarchy reveals a relatively stable, linear dominance hierarchy in this species, with social network structure centered around one particularly dominant individual, interestingly not the largest.

\section{CONCLUSION}

The diversity of methods and study species presented within this RT is testament to burgeoning interest within marine ecology, to understand how population dynamics can be mediated by social behavior (Figure 1). A number of these papers call for more standardized terminology and procedure to better facilitate comparative analyses that explore the evolutionary mechanisms underpinning such widespread social function in marine organisms. Technological developments and associated analyses will continue to assist with the remote measurement of associations and interactions between individuals and at the appropriate scale. This will be key, as we attempt to understand and mitigate the potential impacts of widespread climate-related change to most marine habitats in the near future. 


\section{AUTHOR CONTRIBUTIONS}

DJ conceived the idea for the RT and provided the first draft of the manuscript. JMourier created Figure 1. All authors contributed to the final version.

\section{REFERENCES}

Allen, J., Weinrich, M., Hoppitt, W., and Rendell, L. (2013). Network-based diffusion analysis reveals cultural transmission of lobtail feeding in humpback whales. Science 340, 485-488. doi: 10.1126/science.1231976

Andersson, A. J., MacKenzie, F. T., and Lerman, A. (2005). Coastal ocean and carbonate systems in the high $\mathrm{CO}_{2}$ world of the anthropocene. Am. J. Sci. 305, 875-918. doi: 10.2475/ajs.305.9.875

Croft, D. P., James, R., and Krause, J. (2008). Exploring Animal Social Networks. Princeton, NJ; Oxford: Princeton University Press.

Croft, D. P., Madden, J. R., Franks, D. W., and James, R. (2011). Hypothesis testing in animal social networks. Trends Ecol. Evol. 26, 502-507. doi: 10.1016/j.tree.2011.05.012

Duarte, C. M., Chapuis, L., Collin, S. P., Costa, D. P., Devassy, R. P., Eguiluz, V. M., et al. (2021). The soundscape of the Anthropocene ocean. Science 371, eaba4658. doi: 10.1126/science.aba4658

Elliott, M., Borja, A., and Cormier, R. (2020). Activity-footprints, pressuresfootprints and effects-footprints - walking the pathway to determining and managing human impacts in the sea. Mar. Pollut. Bull. 155, 111201. doi: 10.1016/j.marpolbul.2020.111201

Farine, D. R., and Whitehead, H. (2015). Constructing, conducting, and interpreting animal social network analysis. J. Anim. Ecol. 84, 1144-1163. doi: 10.1111/1365-2656.12418

Franks, D. W., Ruxton, G. D., and James, R. (2010). Sampling animal association networks with the gambit of the group. Behav. Ecol. Sociobiol. 64, 493-503. doi: 10.1007/s00265-009-0865-8

Galezo, A. A., Krzyszczyk, E., and Mann, J. (2018). Sexual segregation in IndoPacific bottlenose dolphins is driven by female avoidance of males. Behav. Ecol. 29, 377-386. doi: 10.1093/beheco/arx177

Goodale, E., Beauchamp, G., and Ruxton, G. D. (2017). Mixed-Species Groups of Animals: Behavior, Community Structure, and Conservation. London: Academic Press.

Haddadi, H., King, A. J., Wills, A. P., Fay, D., Lowe, J., Morton, A. J., et al. (2011). Determining association networks in social animals: choosing spatialtemporal criteria and sampling rates. Behav. Ecol. Sociobiol. 65, 1659-1668. doi: 10.1007/s00265-011-1193-3

Halpern, B. S., Frazier, M., Afflerbach, J., Lowndes, J. S., Micheli, F., O’Hara, C., et al. (2019). Recent pace of change in human impact on the world's ocean. Sci. Rep. 9, 11609. doi: 10.1038/s41598-019-47201-9.

He, P., Maldonado-Chaparro, A. A., and Farine, D. R. (2019). The role of habitat configuration in shaping social structure: a gap in studies of animal social complexity. Behav. Ecol. Sociobiol. 73, 9. doi: 10.1007/s00265-018-2602-7

Krause, J., Croft, D. P., and James, R. (2007). Social network theory in the behavioural sciences: potential applications. Behav. Ecol. Sociobiol. 62, 15-27. doi: 10.1007/s00265-007-0445-8

Krause, J., and Ruxton, G. D. (2002). Living in Groups. Oxford: Oxford University Press.

\section{ACKNOWLEDGMENTS}

We thank all the authors that have contributed to this RT, as well as the Frontiers in Marine Science editorial staff for their support. DJ was funded by the Bertarelli Foundation through the Bertarelli Programme in Marine Science.

Pack, A. A., Herman, L. M., Spitz, S. S., Hakala, S., Deakos, M. H., and Herman, E. Y. K. (2009). Male humpback whales in the Hawaiian breeding grounds preferentially associate with larger females. Anim. Behav. 77, 653-662. doi: 10.1016/j.anbehav.2008.11.015

Perry, C. T., and Alvarez-Filip, L. (2019). Changing geo-ecological functions of coral reefs in the anthropocene. Funct. Ecol. 33, 976-988. doi: 10.1111/1365-2435.13247

Rendell, L., and Whitehead, H. (2001). Culture in whales and dolphins. Behav. Brain Sci. 24, 309-382. doi: 10.1016/B978-0-12-373553-9.00068-7

Schürch, R., Rothenberger, S., and Heg, D. (2010). The building-up of social relationships: behavioural types, social networks and cooperative breeding in a cichlid. Philos. Trans. R. Soc. B Biol. Sci. 365, 4089-4098. doi: $10.1098 /$ rstb.2010.0177

Seebacher, F., and Krause, J. (2019). Epigenetics of social behaviour. Trends Ecol. Evol. 34, 818-830. doi: 10.1016/j.tree.2019.04.017

Shizuka, D., and McDonald, D. B. (2012). A social network perspective on measurements of dominance hierarchies. Anim. Behav. 83, 925-934. doi: 10.1016/j.anbehav.2012. 01.011

Sosa, S., Jacoby, D. M. P., Lihoreau, M., and Sueur, C. (2021). Animal social networks : towards an integrative framework embedding social interactions, space and time. Methods Ecol. Evol. 2021, 4-9. doi: 10.1111/2041-210X.13539

Sridhar, H., Beauchamp, G., and Shanker, K. (2009). Why do birds participate in mixed-species foraging flocks? A large-scale synthesis. Anim. Behav. 78, 337-347. doi: 10.1016/j.anbehav.2009.05.008

Villegas-Ríos, D., Jacoby, D. M. P., and Mourier, J. (2022). Social networks and the conservation of fish. Commun. Biol (In press). doi: 10.1038/s42003-022-03138-w

Conflict of Interest: The authors declare that the research was conducted in the absence of any commercial or financial relationships that could be construed as a potential conflict of interest.

Publisher's Note: All claims expressed in this article are solely those of the authors and do not necessarily represent those of their affiliated organizations, or those of the publisher, the editors and the reviewers. Any product that may be evaluated in this article, or claim that may be made by its manufacturer, is not guaranteed or endorsed by the publisher.

Copyright (C) 2022 Jacoby, Brown, Croft, Mann and Mourier. This is an open-access article distributed under the terms of the Creative Commons Attribution License (CC $B Y)$. The use, distribution or reproduction in other forums is permitted, provided the original author(s) and the copyright owner(s) are credited and that the original publication in this journal is cited, in accordance with accepted academic practice. No use, distribution or reproduction is permitted which does not comply with these terms. 